\title{
Pengaruh Ketidakseimbangan Beban Terhadap Efesiensi Transformator Distribusi Studi Gardu PT PLN (Persero) Area Bekasi
}

\author{
Rio Afrianda1; Afifah Annisa Nurul Huda²; samsurizal ${ }^{3}$ \\ 1, 2, 3 Teknik Elektro (Institut Teknologi PLN) \\ ${ }^{3}$ samsurizal@itpln.ac.id
}

\begin{abstract}
Load unbalance in an electric power system often occur to meet consumer needs. Distribution of the load that was initially evenly will experience an unbalance when the burdens. As a result, current arises in the transformer neutral, current flowing in the transformer neutral causes losses, losses in the neutral conductor transformer and current flowing to the ground. Technically, if these losses occur continuously, it will be detrimental to PLN and can reduce transformer efficiency. For the supply of electricity to remain stable and continuity, it must be overcome.
\end{abstract}

Keywords: Load unbalance, losses, transformer efficiency

\begin{abstract}
ABSTRAK
Ketidak seimbangan beban pada suatu sistem tenaga listrik sering terjadi untuk dapat memenuhi kebutuhan konsumen. Pembagian beban yang awalnya merata mengalami ketidakseimbangan waktu menyalanya beban-beban tersebut. Akibatnya timbul lah arus di netral trafo, arus yang mengalir di netral trafo ini menyebabkan rugi-rugi, yaitu rugi-rugi pada penghantar netral trafo dan arus yang mengalir ke tanah. Secara teknis, jika losses ini terjadi berkelanjutan maka akan dapat merugikan PLN dan dapat menurunkan efisiensi trafo. Agar penyuplaian listrik tetap stabil dan kontinuitas maka hal tersebut harus dapat teratasi.
\end{abstract}

Kata kunci: Ketidak seimbangan beban, losses, efisiensi trafo 


\section{PENDAHULUAN}

Ketidak seimbangan beban terjadi pada trassformator antar tiap fasa yaitu fasa $R$, fasa $S$, dan fasa $T$ dan inilah yang menimbulkan arus mengalir pada netral trafo. Arus yang mengalir pada netral trafo ini yang menyebabkan rugi-rugi daya[1][4]. Beban dikatakan seimbang apabila pada masing-masing fasa mengalir arus yang sama besarnya, namun pada kenyataannya selalu ada kemungkinan ketidak seimbangan sehingga arusnya tidak seimbang[3][5].

Pada transformator akibat adanya arus netral yang mengalir pada penghantar trafo dapat mengakibatkan rugi-rugi dan efisiensi yang menurun[2][6]. Apabila efisiensi transformator menurun dapat berakibat pada nilai umur trafo yang berkurang sehingga kehandalan salah satu dalam sistem tenaga listrik pun ikut mengalami penurunan kualitas pelayanan dalam memenuhi kebutuhan pelanggan. Namun jika dilakukan pemeliharan secara berkala pada setiap transformator tersebut maka kualitas nya akan tetap terjaga, seperti mengganti minyak pada trafo dan melakukan pengecekan pada setiap gardugardunya[7][8].

\section{METODE/PERANCANGAN PENELITIAN}

\subsection{Prinsip Kerja Transformator}

Transformator terdiri atas dua buah kumparan yaitu primer dan sekunder yang sifatnya induktif. Kedua kumparan ini terpisah secara elektris namun berhubungan secara magnetis melalui jalur yang memiliki reluktansi rendah. Apabila kumparan primer dihubungkan dengan sumber tegangan bolak-balik maka fluks bolak balik akan muncul di dalam inti yang dilaminasi, karena kumparan tersebut membentuk rangkaian tertutup maka mengalirlah arus primer. Akibat adanya fluks di kumparan primer maka di kumparan primer terjadi induksi (self induction) dan terjadi pula induksi di kumparan sekunder karena pengaruh induksi dari kumparan primer atau disebut sebagai induksi bersama yang menyebabkan timbulnya fluks magnet di kumparan sekunder, maka mengalirlah arus sekunder jika rangkaian sekunder di bebani, sehingga energi listrik dapat ditransfer keseluruhan (secara magnetisasi) dimana[4][5].

$$
e=(-) N \frac{\mathrm{d} \emptyset}{d t}(\text { Volt })
$$

Dimana ;

$\mathrm{e} \quad=$ Gaya geral listrik

$\mathrm{N} \quad=$ Jumlah lilitan

$\emptyset \quad=$ = Perubahan fluks magnet (weber/sec)

\subsection{Arus Beban Penuh pada Transformator}

Penurunan tegangan maksimum pada beban penuh, yang dibolehkan dibeberapa titik pada jaringan distribusi adalah (SPLN 72,1987)[10]:

1. SUTM, $5 \%$ dari tegangan kerja bagi sistem radial

2. SKTM, $2 \%$ dari tegangan kerja pada sistem spindel dan gugus.

3. Trafo distribusi, $3 \%$ dari tegangan kerja

4. Saluran tegangan rendah, $4 \%$ dari tegangan kerja tergantung kepadatan beban. 
5. Sambungan rumah, $1 \%$ dari tegangan nominal. Distribusi yang tepat juga rating yang sesuai dengan kebutuhan beban akan menjaga tegangan jatuh pada konsumen dan otomatis akan menaikkan efisiensi penggunaan Transformator Distribusi. Transformator Distribusi merupakan salah satu peralatan yang perlu dipelihara dan dipergunakan sebaik serta seefisien mungkin, sehingga dapat menjaga keandalan/kontinuitas pelayanan yang terjamin mutunya. (Dendi, 2014)[4].

Daya transformator bila ditinjau dari sisi tegangan tinggi (primer) dapat dirumuskan sebagai berikut :

$$
S=\sqrt{ } 3 \mathrm{VI}
$$

\section{Dimana:}

$\mathrm{S}=$ Daya transformator (VA

$\mathrm{V} \quad=$ Tegangan sisi primer transformator $(\mathrm{V})$

I = Arus jala-jala $(\mathrm{A})$

Menentukan arus beban penuh (full load) dapat menggunakan rumus:

$$
I F L=(-) \frac{\mathrm{S}}{\sqrt{3 . V}}(\text { Volt })
$$

\section{Dengan:}

$\mathrm{IFL} \quad=$ Arus beban penuh

$\mathrm{S}=$ Daya transformator (VA)

$\mathrm{V} \quad=$ Tegangan sisi sekunder transformator $(\mathrm{V})$

Dengan demikian untuk menghitung presentase pembebanannya menggunakan persamaan:

$$
\% b=(-) \frac{\mathrm{lph}}{\mathrm{llf}} \times 100 \%
$$

Dengan;

$\% \mathrm{~b}=$ Presentase pembebanan $(\%)$

Iph $\quad=$ Arus fasa $(A)$

IFL $\quad=$ Arus beban penuh $(A)$

\subsection{Rugi-Rugi Transformator}

Ada beberapa rugi-rugi yang terjadi pada transformator yaitu rugi pada saat trafo berbeban dan tanpa beban, rugi pada saat berbeban merupakan fungsi dari arus beban terutama rugi tembaga. Berikut adalah rugi - rugi yang mengalir pada transformator: 
1. Losses akibatnya adanya arus pada penghantar netral trafo dapat dirumuskan sebagai berikut

$\mathrm{PN}=\mathrm{IN} \mathrm{N}^{2} \mathrm{R} / \mathrm{V}$

(5)

Dimana:

PN = Losses yang timbul pada penghantar netral (Watt)

$\mathrm{IN}^{2} \quad=$ Arus yang mengalir melalui kawat netral $(\mathrm{A})$

$\mathrm{R} / \mathrm{V}=$ Tahanan pada kawat nertal (Ohm)

2. Losses akibat adanya arus ground dapat dirumuskan sebagai berikut:

$\mathrm{P} G=I G^{2} \cdot \mathrm{R} G$

(6)

Dimana:

$\mathrm{PG} \quad=$ Losses yang timbul pada penghantar netral (Watt)

$G^{2} \quad=$ Arus yang mengalir melalui kawat netral $(\mathrm{A})$

$\mathrm{RG} \quad=$ Tahanan pada kawat netral $(\mathrm{Ohm})$

3. Efisiensi pada transformator dapat ditentukan dengan persamaan

$\eta=P o / P i n$

Dimana:

Po $\quad=$ Daya keluaran (Watt)

Pin $\quad=$ Daya Masukan (Watt)

\section{HASIL DAN PEMBAHASAN}

Ketidakseimbangan beban terjadi apabila pada salah satu fasa mempunyai beban yang lebih besar dibandingkan beban fasa yang lainnya. Akibat ketidakseimbangan beban tersebut terjadilah arus yang mengalir pada netral trafo yang menyebabkan terjadinya rugirugi (losses). Losses ini dapat berpengaruh terhadap efisensi transformator, yang mana apabila efisiensi trafo menurun akan mengurangi kualitas trafo tersebut.

\subsection{Data Transformator pada saat Beban Rendah (Siang Hari)}

Berikut adalah data hasil pengukuran beban trafo dengan kapasitas $250 \mathrm{kVA}$ dan dilakukan pengukuran pada waktu siang hari. 
Tabel 1. Data Pengukuran Gardu pada saat Siang Hari Pengukuran Gardu Distribusi

\begin{tabular}{cccccccccc} 
Jurusan & Tipe & Penampang & $\mathrm{R}$ & $\mathrm{S}$ & $\mathrm{T}$ & $\mathrm{N}$ & $\begin{array}{c}\mathrm{R}-\mathrm{N} \\
\text { (Volt) }\end{array}$ & $\begin{array}{c}\mathrm{S}-\mathrm{N} \\
\text { (Volt) }\end{array}$ & $\begin{array}{c}\text { T-N } \\
\text { (Volt) }\end{array}$ \\
\hline 1 & $\mathrm{CU}$ & $95 \mathrm{~mm}^{2}$ & 50 & 56 & 22 & 35 & 290 & 230 & 230 \\
2 & $\mathrm{CU}$ & $95 \mathrm{~mm}^{2}$ & 75 & 81 & 34 & 41 & 291 & 229 & 229 \\
\hline
\end{tabular}

\subsection{Data Transformator pada saat Beban Rendah (Siang Hari)}

Berikut adalah data hasil pengukuran beban trafo dengan kapasitas 250 kVA dan dilakukan pengukuran pada waktu siang hari.

Tabel 2. Data Pengukuran Gardu pada saat Siang Malam

\begin{tabular}{|c|c|c|c|c|c|c|c|c|c|}
\hline \multicolumn{10}{|c|}{ Pengukuran Gardu Distribusi } \\
\hline Jurusan & Tipe & Penampang & $\mathrm{R}$ & S & $\mathrm{T}$ & $\mathrm{N}$ & $\begin{array}{c}\text { R-N } \\
\text { (Volt) }\end{array}$ & $\begin{array}{c}\text { S-N } \\
\text { (Volt) }\end{array}$ & $\begin{array}{c}\text { T-N } \\
\text { (Volt) }\end{array}$ \\
\hline 1 & CU & $95 \mathrm{~mm}^{2}$ & 157 & 104 & 42 & 103 & 226 & 229 & 229 \\
\hline 2 & CU & $95 \mathrm{~mm}^{2}$ & 78 & 102 & 17 & 79 & 225 & 230 & 230 \\
\hline \multicolumn{10}{|c|}{ Tahanan $\mathrm{RN}=0,2509 \mathrm{Ohm}, \mathrm{RG}=1,91 \mathrm{Ohm}$} \\
\hline
\end{tabular}

\subsection{Pembahasan}

Untuk menghitung efisiensi pada transformator yang dipengaruhi oleh adanya beberapa rugi - rugi daya, rugi inti besi, rugi tembaga, rugi yang mengalir pada penghantar netral dan rugi yang mengalir pada tanah. Untuk itu akan mencari nilai daya yang masuk terlebih dahulu.

Daya masuk (PIN) Transformator adalah :

$$
\mathrm{PIN}=\mathrm{S} \times \operatorname{Cos} \emptyset
$$

Dimana cos yang digunakan adalah 0,85 yang diasumsikan untuk pemakaian rumah tangga oleh PLN

$$
\begin{aligned}
\mathrm{PIN} & =\mathrm{S} \times \operatorname{Cos} \varnothing \\
& =250.000 \mathrm{VA} \times 0,85 \\
& =212.500 \mathrm{Watt} \\
& =212.5 \mathrm{Kw}
\end{aligned}
$$

\subsection{Menentukan Presentase Pembebanan Transformator}

\subsubsection{Pegukuran saat beban rendah pada gardu (Siang Hari)}

Terlebih dahulu dihitung nilai beban penuh pada transformator dengan menggunakan persamaan: 


$$
I F L=\frac{\mathrm{S}}{\sqrt{3} . \mathrm{V}}=\frac{250 \mathrm{KVA}}{\sqrt{3.250} \mathrm{~V}}=577.35 \mathrm{~A}
$$

Setelah itu menghitung persentase pembebanan per fasa dengan menggunakan persamaan:

$$
\begin{aligned}
& \% b=\frac{\text { lph }}{\text { llf }} \times 100 \% \\
& \mathrm{IR}=125 \mathrm{~A} \\
& \text { IS }=137 \mathrm{~A} \\
& \mathrm{IT}=56 \mathrm{~A} \\
& \% b R=\frac{125 \mathrm{~A}}{577.35} \times 100 \%=21,65 \% \\
& \% b S=\frac{137 \mathrm{~A}}{577.35} \times 100 \%=23,75 \% \\
& \% b T=\frac{56 \mathrm{~A}}{577.35} \times 100 \%=9,69 \%
\end{aligned}
$$

Jadi Rata-rata pembebanan adalah :

$$
\begin{aligned}
& =\frac{\% b R+\% b S+\% b T}{3} \\
& =\frac{21,65+23,72+9,69}{3} \\
& =18,35 \%
\end{aligned}
$$

\subsubsection{Pegukuran saat beban rendah pada gardu (Siang Malam)}

Terlebih dahulu dihitung nilai beban penuh pada transformator dengan menggunakan persamaan:

$$
I F L=\frac{\mathrm{S}}{\sqrt{3 . \mathrm{V}}}=\frac{250 \mathrm{KVA}}{\sqrt{3.250} \mathrm{~V}}=577.35 \mathrm{~A}
$$

Setelah itu menghitung persentase pembebanan per fasa dengan menggunakan persamaan:

$$
\begin{aligned}
& \% b=\frac{\text { lph }}{\text { llf }} \times 100 \% \\
& \mathrm{IR}=93 \mathrm{~A} \\
& \mathrm{IS}=206 \mathrm{~A} \\
& \mathrm{IT}=56 \mathrm{~A}
\end{aligned}
$$




$$
\begin{aligned}
& \% b R=\frac{93 \mathrm{~A}}{577.35} \times 100 \%=16,10 \% \\
& \% b S=\frac{206 \mathrm{~A}}{577.35} \times 100 \%=35,68 \% \\
& \% b T=\frac{59 \mathrm{~A}}{577.35} \times 100 \%=10,21 \%
\end{aligned}
$$

Jadi Rata-rata pembebanan adalah :

$$
\begin{aligned}
& =\frac{\% b R+\% b S+\% b T}{3} \\
& =\frac{16,10+35,68+10,21}{3} \\
& =20,66 \%
\end{aligned}
$$

\subsection{Perhitungan Rugi-Rugi pada Transformator}

\subsubsection{Perhitungan Losses Trafo pada Siang Hari}

Untuk rugi besi pada trafo besar nilainya adalah tetap, tidak dipengaruhi oleh nilai bebannya. Dapat total losses trafo adalah dengan menggunakan persamaan berikut:

$$
\begin{aligned}
\text { Losses Trafo } & =\mathrm{Pb}+a^{2} \times \mathrm{P} c u \\
& =550+(0,18)^{2}+3800 \\
& =673,12 \mathrm{Watt}=0,673 \mathrm{Kw}
\end{aligned}
$$

Persentase losses terhadap daya trafo:

$$
\begin{aligned}
& =\frac{0,673}{212,5} \times 100 \% \\
& =0,31 \%
\end{aligned}
$$

\subsubsection{Perhitungan Losses Trafo pada Malam Hari}

Untuk rugi besi pada trafo besar nilainya adalah tetap, tidak dipengaruhi oleh nilai bebannya. Dapat total losses trafo adalah dengan menggunakan persamaan berikut:

$$
\begin{aligned}
\text { Losses Trafo } & =\mathrm{Pb}+a^{2} \times \mathrm{P} c u \\
& =550+(0,20)^{2}+3800 \\
& =700 \text { Watt }=0,702 \mathrm{Kw}
\end{aligned}
$$

Persentase losses terhadap daya trafo:

$$
\begin{aligned}
& =\frac{0,702}{212,5} \times 100 \% \\
& =0,33 \%
\end{aligned}
$$




\subsection{Perhitungan Ketidak seimbangan Beban}

Diperoleh untuk koefisien a,b, dan $\mathrm{c}$ dengan besar arus fasa dalam keadaan seimbang sama dengan besar rata-rata

$$
\begin{aligned}
& I R=a \\
& I S=b \\
& I T=c
\end{aligned}
$$

Maka :

$$
\begin{aligned}
& a=\frac{I R}{\text { I rata }- \text { rata }}=\frac{125}{106}=1,17 \\
& b=\frac{I R}{\text { I rata }- \text { rata }}=\frac{137}{106}=1,29 \\
& c=\frac{I R}{\text { I rata }- \text { rata }}=\frac{56}{106}=0,52
\end{aligned}
$$

Dengan demikian, rata-rata ketidakseimbangannya bisa ditentukan dengan persamaan:

$$
\begin{aligned}
& =\frac{(\mathrm{Ia}-1 \mathrm{I}+\mathrm{Ib}-1 \mathrm{I}+\mathrm{Ic}-1 \mathrm{I})}{3} \times 100 \% \\
& =31 \%
\end{aligned}
$$

\subsection{Perhitungan Rugi Daya yang Mengalir Pada Penghantar Netral}

Berdasarkan data pada table untuk menghitung nilai rugi yang mengalir pada penghantar netral menggunakan persamaan:

$$
\begin{aligned}
\mathrm{RN} & =1,3 \times \mathrm{RDC} \\
& =1,3 \times 0,193 \\
& =0,2509 \mathrm{ohm}
\end{aligned}
$$

\section{Menghitung Rugi Daya Penghantar Netral pada Saat Siang}

$$
\begin{aligned}
\mathrm{PN} & =\mathrm{IN}^{2} \times \mathrm{RN} \\
& =(76)^{2} \times 0,2509 \mathrm{ohm} \\
& =1,449.1984 \text { watt } \\
& =1,499 \mathrm{Kw}
\end{aligned}
$$

Persentase Losses terhadap daya trafo :

$$
\begin{aligned}
& =\frac{1,499 \mathrm{KW}}{212,5 \mathrm{Kw}} \times 100 \% \\
& =1,68 \%
\end{aligned}
$$




\section{Menghitung Rugi Daya Penghantar Netral pada Saat Malam}

$$
\begin{aligned}
\mathrm{PN} & =\mathrm{IN}^{2} \times \mathrm{RN} \\
& =(182)^{2} \times 0,2509 \mathrm{ohm} \\
& =8,310.8116 \text { watt } \\
& =8,310 \mathrm{Kw}
\end{aligned}
$$

Persentase Losses terhadap daya trafo :

$$
\begin{aligned}
& =\frac{8,310 \mathrm{KW}}{212,5 \mathrm{Kw}} \times 100 \% \\
& =3,9 \%
\end{aligned}
$$

\subsection{Efisiensi Transformator}

Untuk menentukan nilai efisiensi yang dipengaruhi oleh adanya rugi-rugi pada transformator saat siang hari dan malam hari.

\subsubsection{Perhitungan Efisiensi pada Saat Siang Hari}

$$
\begin{aligned}
\eta \quad & =\frac{p \text { out }}{\mathrm{p} \text { in }} \\
& =\frac{P \text { input-Losses Trafo-P pada penghantar }-P \text { pada Grounding }}{\mathrm{p} \mathrm{in}} \\
& =\frac{212,5-0,673-1,449-2,339}{212,5} \\
& =\frac{207,989}{212,5} \\
& =97 \%
\end{aligned}
$$

\subsubsection{Perhitungan Efisiensi pada Saat Malam Hari}

$$
\begin{aligned}
\eta & =\frac{p \text { out }}{\mathrm{p} \text { in }} \\
& =\frac{P \text { input }- \text { Losses Trafo-P pada penghantar }-P \text { pada Grounding }}{\mathrm{p} \mathrm{in}} \\
& =\frac{212,5-0,702-8,310-6,250}{212,5} \\
& =\frac{197,283}{212,5} \\
& =92 \%
\end{aligned}
$$

Tabel 3. Hasil Analisa Perhitungan

\begin{tabular}{ccccccc}
\hline Waktu & $\begin{array}{c}\text { Pembebanan } \\
(\%)\end{array}$ & Ketidakseimbangan (\%) & P T & P N & P G & $\eta$ \\
\hline Siang & 18,35 & 31 & 0,673 & 1,499 & 2,339 & 97 \\
Malam & 20,66 & 48 & 0,702 & 8,310 & 6,205 & 92 \\
\hline
\end{tabular}

Dari beberapa faktor di atas, ada beberapa solusi yang perlu dilakukan untuk dapat meminimalisir terjadinya ketidakseimbangan beban pada saat di lapangan, beberapa diantaranya dilakukan dengan memutar salah satu fasa yang berada pada PHB-TR, lalu pindah beban per pelanggan dengan memindahkan beban yang pincang, dan dilakukan 
pindah beban dari jurusan satu ke jurusan lain yang mana apabila beban itu berlebih akan dibagi ke jurusan yang nilai bebannya kurang.

Jadi implikasi penelitian ini untuk mengetahui persiapan kedepan dalam mengatasi permasalahan yang terjadi pada Transformator yang mengalami ketidak seimbangan beban dengan diharapkan melakukan solusi putar fasa, pindah beban per pelanggan dan pindah beban atau pecah beban.

\section{KESIMPULAN DAN SARAN}

Berdasarkan perhitungan dan hasil dari pembahasan di atas, penulis dapat menarik kesimpulan bahwa :

1. Transformator pada Gardu di Area Bekasi Kota dikatakan tidak seimbang karena arus yang mengalir pada fasa berbeda

2. Ketidakseimbangan terjadi apabila arus yang mengalir pada fasa nilainya berbeda, ketidakseimbangan tertinggi terjadi pada waktu malam hari yaitu sebesar $31 \%$

3. Rugi - rugi terjadi akibat adanya arus yang mengalir pada netral, yang mana rugi - rugi terjadi paling tinggi pada waktu malam hari yaitu pada waktu beban puncak.

4. Waktu beban puncak adalah waktu dimana pemakaian energi listrik yang meningkat dari waktu siang hari, oleh karena itu pada waktu malam hari nilai ketidak seimbangan beban, rugi - rugi pun ikut meningkat dan nilai efisiensi transformator menurun. Maka nilai efisiensi terendah terjadi pada malam hari yaitu $92 \%$.

\section{DAFTAR PUSTAKA}

[1] Anshari, Riza. (2013). Rugi dan Efisiensi Transformator

[2] Aldy Y A, Dimas. (2018). Pengaruh Pembebanan Terhadap Umur Transformator Tenaga di Gardu Induk Palur 150KV

[3] Isnanto, Yanuar dkk. (2006). Pengaruh Ketidakseimbangan Beban Terhadap Arus Netral Dan Losses Pada Transformator Distribusi. Universitas Kristen Petra

[4] Kadir, Abdul. (1989). Transformator. Jakarta: PT. Alex Media Komputindo

[5] Marsudi, Djiteng. Operasi Sistem Tenaga Listrik. Jakarta Selatan: Balai Penerbit \& Humas ISTN

[6] Muhaimin Afif, Adri. (2014). Pembagian Jaringan Distribusi dan Sistem Proteksinya

[7] Purwanto, Rizky. (2019). Analisa Pengaruh Ketidakseimbangan Beban Terhadap Rugi-Rugi Daya Pada Saluran Jaringan TegangancRendah (PT. PLN Rayon Belanti Padang). Universitas Andalas

[8] Santosi, Yorri. (2019). Analisa Dampak Ketidakseimbangan Beban Terhadap Losses Pada Jaringan Kelistrikan Fakultas Pertanian Universitas Andalas

[9] Samsurizal, S., Hadinoto, B. (2020). Studi Analisis Dampak Overload Transformator Terhadap Kualitas Daya Di PT. PLN (Persero) UP3 Pondok Gede. KILAT, 9(1), 136142.

[10] SPLN 72: Spesifikasi Desain Untuk Jaringan Tegangan Menengah dan Jaringan Tegangan Rendah

[11] SPLN 41-1:1991 Persyaratan Penghantar Tembaga Dan Aluminium Untuk Kabel Listrik Berisolasi Anshari, Riza. (2013). Rugi dan Efisiensi Transformator 